\title{
Molecular data supports the inclusion of Ildobates neboti Español in Zuphiini (Coleoptera: Carabidae: Harpalinae)
}

\author{
Ignacio Ribera, Sergio Montagud, Santiago Teruel \& Xavier Bellés
}

\begin{abstract}
Ribera, I., Montagud, S., Teruel, S. \& Bellés, X. 2006: Molecular data supports the inclusion of Ildobates neboti Español in Zuphiini (Coleoptera: Carabidae: Harpalinae). — Entomol. Fennica 17: 207-213.

The phylogenetic relationships of Ildobates neboti Español (Coleoptera: Carabidae: Harpalinae) were investigated based on three nuclear genes (full $18 \mathrm{~S}$ rRNA, and a fragment of each $28 \mathrm{~S}$ rRNA and wingless). We compiled a data set using published sequences of 32 members of Harpalinae including one example each of Dryptini (genus Desera), Galeritini (Galerita) and Zuphiini (Thalpius), plus three Brachininae as outgroups. These three tribes form the "Dryptitae", within which various relationships of Ildobates had been proposed. The analyses of the data matrix using parsimony (with equally weighted and reweighted characters) and Bayesian posterior probabilities all support the monophyly of the three tribes in "Dryptitae", as well as a closest relationship of Ildobates with Thalpius to the exclusion of Desera plus Galerita. This confirms the previous inclusion of Ildobates among the Zuphiini, and corroborates current taxonomic classifications based on morphological criteria.
\end{abstract}

I. Ribera, Departamento de Biodiversidad y Biología Evolutiva, Museo Nacional de Ciencias Naturales, José Gutiérrez Abascal 2, 28006 Madrid, Spain; E-mail: i.ribera@mncn.csic.es

S. Montagud and S. Teruel, Museu Valencià d'Història Natural (Fundación Entomológica Torres Sala). Paseo de la Pechina 15, 46008 Valencia, Spain; Email: Sergio.Montagud@uv.es

X. Bellés, Department of Physiology and Molecular Biodiversity, Institut de Biologia Molecular de Barcelona (CID, CSIC), Jordi Girona 18, 08034 Barcelona,Spain; E-mail:xbragr@cid.csic.es

Received 12 December 2005, accepted 6 April 2006

\section{Introduction}

Among the diverse fauna of Coleoptera of the Iberian peninsula, Ildobates neboti Español stands out as one of the most emblematic taxa, both because of its morphology [with extreme modifications for cave life (Español 1966, Bellés 1987)] and its rarity, being known for only a handful of specimens from three caves in the
Mediterranean coast of Spain, in the province of Castellón (Ortuño et al. 2004). Although in the original description the species was identified as a "Dryptidae" (Español 1966), its precise relationships were contentious, with characters relating it to several of the tribes within the group [see Ortuño et al. (2004) for a summary of the taxonomic history of the species]. The current consensus view seems to include Ildobates among 
Table 1. Sequences used in the study. Taxonomic ordination follows Löbl \& Smetana (2003).

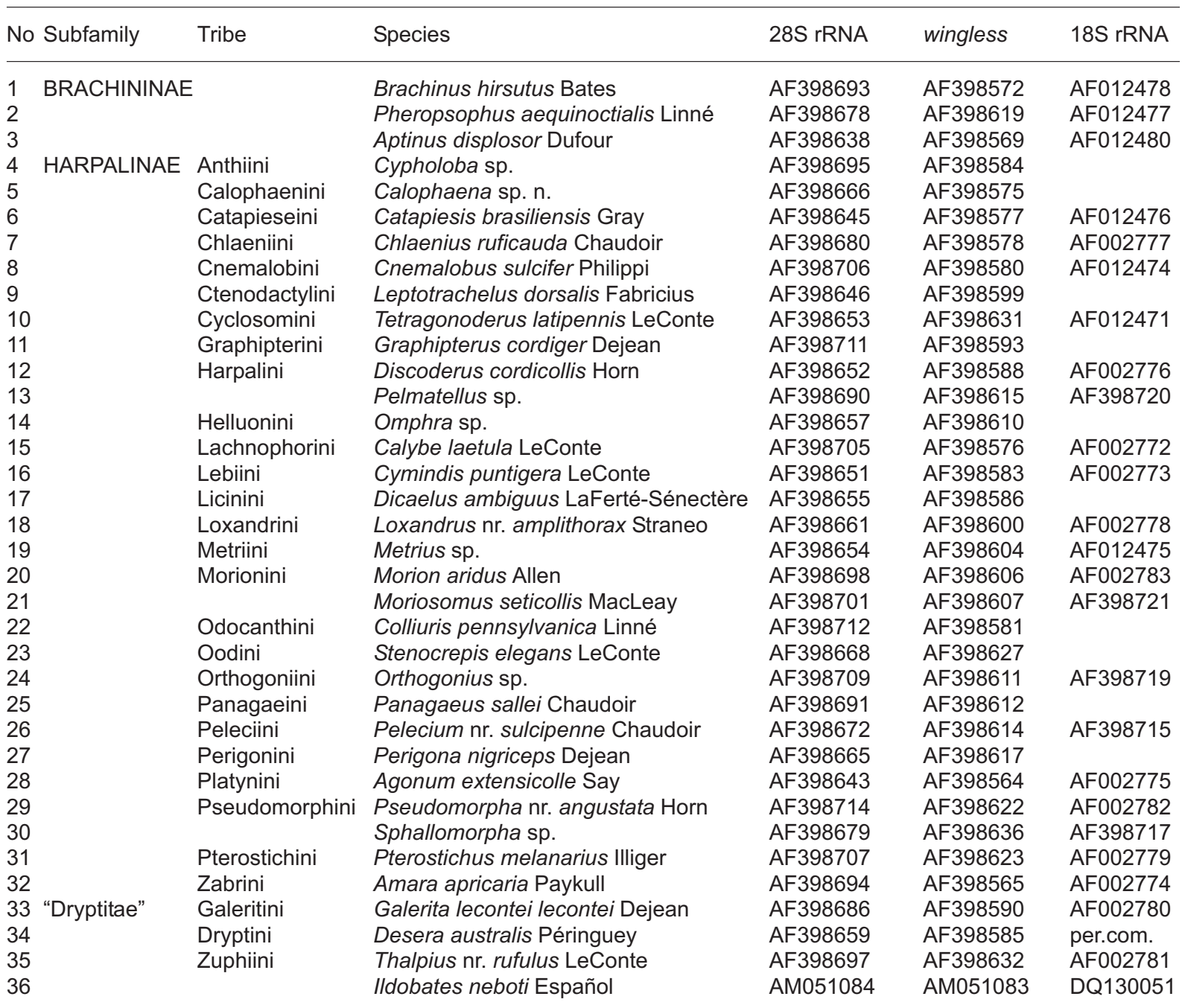

the Zuphiini, as reflected in the most recent taxonomic catalogues [both Iberian (Serrano 2003) and Palaearctic (Löbl \& Smetana 2003)] and in morphological studies (Ortuño et al. 2004). At present, however, there are no phylogenetic studies (either morphological or molecular) including Ildobates, therefore all discussions on its relationships have been purely descriptive.

In this contribution we present the first formal phylogenetic study including Ildobates neboti, based on sequences of three nuclear gene fragments and including a good taxonomic coverage of Harpalinae (with one example each of the three tribes to which Ildobates has been related). Our aim is to provide for the first time a sound phylogenetic ground for the taxonomic placement of this emblematic species, as well as to make feasible future studies on its evolutionary and geographic origin by the identification of its potential closest living relatives.

\section{Material and methods}

\subsection{DNA extraction and sequencing}

Genomic DNA was obtained through a standard phenol-chloroform extraction using abdominal 
tissue (voucher specimen kept in X. Bellés coll., DNA aliquots kept in the MNCN ref. 6409). Three nuclear fragments were amplified, those for which there were enough published sequences of related species: the full $18 \mathrm{~S}$ rRNA, and a fragment of each wingless and 28S rRNA.

The $18 \mathrm{~S}$ rRNA sequence was obtained by direct sequencing of four overlapping fragments amplified with internal primers (see Shull et al. 2001 for details of the primers and PCR conditions used). Both forward and reverse sequences were obtained for each fragment, which were contigged and edited using Sequencher 4.2 (GeneCodes Corporation). The wingless and 28S rRNA sequences were obtained using the primers and the PCR protocol described in Ober (2002). Accession numbers for the sequences are DQ130051 (18S rRNA), AM051083 (wingless) and AM051084 (28S rRNA) (Table 1).

\subsection{Additional molecular data}

We restricted our analyses to Harpalinae, as the inclusion of Ildobates within this clade is not contentious. We considered Brachininae as the outgroup, following Ober (2002) and Ribera et al. (2005). Sequences were compiled for all species of Harpalinae and Brachininae for which the three studied fragments were available ( 25 species), plus one example of each of the Harpalinae tribes for which no $18 \mathrm{~S}$ rRNA was available (ten additional species; Table 1). Sequences were obtained from Maddison et al. (1998) (GenBank accession numbers AF002772-AF002783), Maddison et al. (1999) (7 sequences among AF012471-AF012480) and Ober (2002) (5 sequences among AF398715-AF398721) (Table 1). Wingless and $28 \mathrm{~S}$ rRNA sequences were obtained from Ober (2002) (35 sequences of each among AF398569-AF398636 and AF398638AF398564, respectively) (Table 1). The $18 \mathrm{~S}$ rRNA sequence of Desera australis Peringuey (Harpalinae, Dryptini) was obtained from D. Maddison (personal communication; June 2005).

Preliminary searches were conducted with the 28S rRNA and wingless genes alone to test for the possibility that Ildobates could be related to any of the tribes with missing 18S rRNA sequences. As this was not the case, a reduced dataset was constructed with only the species for which all genes were available (26 including Ildobates), and all subsequent analyses were conducted with this dataset.

\subsection{Phylogenetic analyses}

Three hyper-variable regions of the $18 \mathrm{~S}$ rRNA gene and six of the 28S rRNA gene were excluded from the analyses, and the remaining sequence was aligned by hand. To align the wingless gene we translated the nucleotide sequence with McClade 4.0 (Maddison \& Maddison 2000), and aligned the aminoacid sequence manually. The nucleotide sequence was thus aligned using the aminoacid sequence as a template. An additional dataset was constructed with the only four species of "Dryptitae" included in the analyses (Table 1), with the full sequences (including hypervariable regions), which were aligned by hand. This was aimed to increase the support for the internal nodes within the group.

Parsimony analysis was conducted in PAUP* version 4.0b10 (Swofford 2002) using TBR heuristic searches with 1,000 random sequence addition replicates. In all searches gaps were coded as a missing character state. To increase resolution, characters were re-weighted according to the rescaled consistency index (Farris 1969), and new heuristic searches conducted starting with the trees obtained with equally weighted characters. Node support was measured with nonparametric bootstrapping with 1,000 pseudo-replicates of 100 random sequence additions each.

Previous analyses including the sequences used in this study (Maddison et al. 1998, 1999, Ober 2002, Ribera et al. 2005) showed the likely presence of artefacts due to the distorting effects of long branches (Felsenstein 1978). Therefore, we conducted additional analyses using modelbased phylogenetic methods, which should in principle be less sensitive than parsimony to the biases introduced by highly saturated or homoplasious data (e.g. Swofford et al. 1996, Felsenstein 2004).

The optimal model of nucleotide substitution was determined with Modeltest 3.7 (Posada \& Crandall 1998), for the three genes separately. In all cases a generalised time reversible (GTR) 


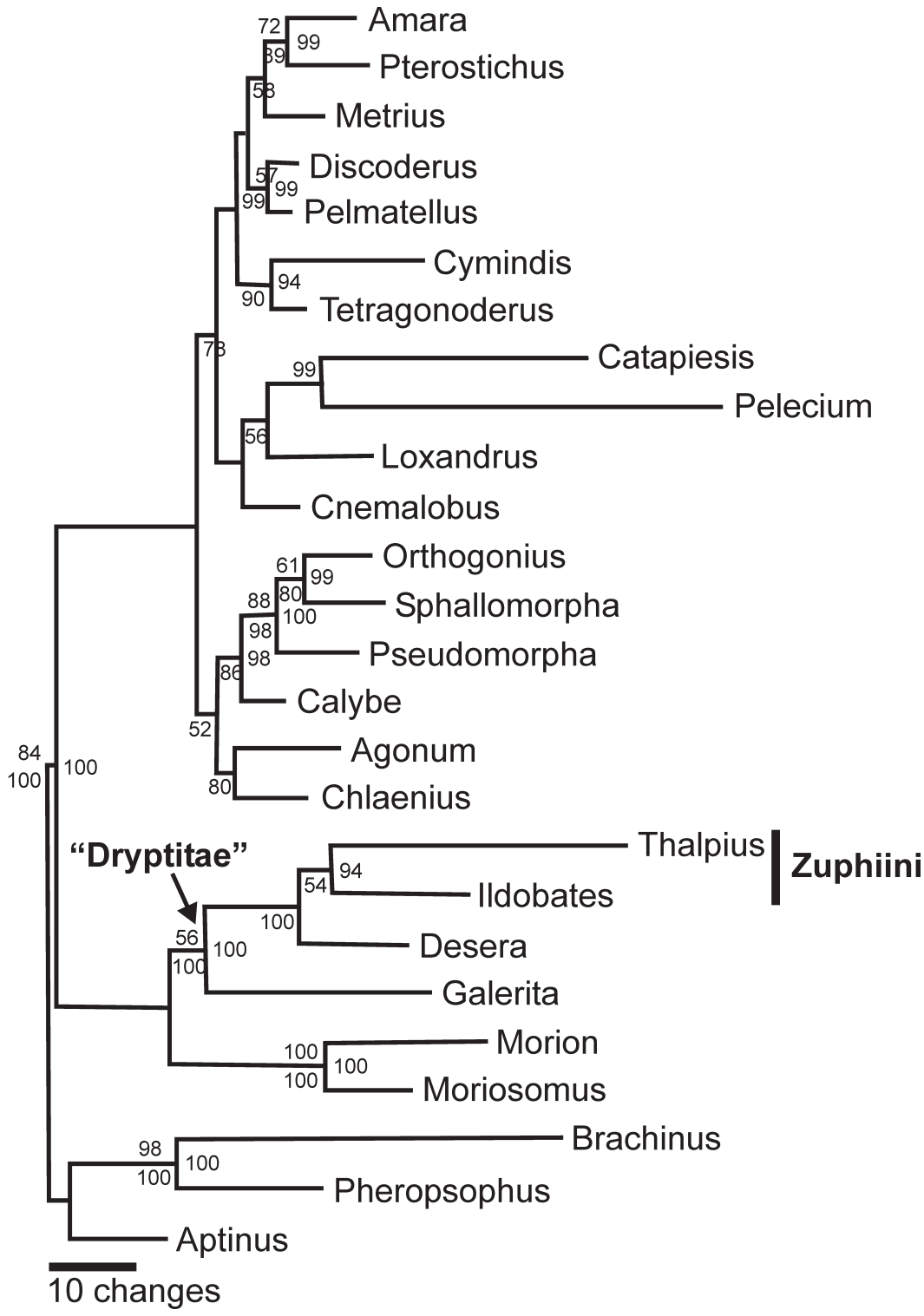

Fig. 1. Phylogram of the single most parsimonious tree resulting from the heuristic search on the re-weighted combined dataset. Numbers above branches, bootstrap support values on the equally weighted dataset; below branches, bootstrap support values on the re-weighted dataset; inside nodes, posterior Bayesian probabilities of the search in MrBayes (×100) (see Methods for details). model (Tavaré 1986) with gamma distributed among site rate variation and estimating the proportion of invariable sites (Yang 1993) was selected as the best fit to the data. To analyse the data we used Bayesian probabilities (Rannala \& Yang 1996) as implemented in the computer program MrBayes 3.1 (Huelsenbeck \& Ronquist 2001, Ronquist \& Huelsenbeck 2003), as it allows the estimation of different evolutionary models for the user-defined data partitions. The parameters of the three partitions (i.e., genes) were estimated independently. Two independent searches were conducted using the default priors (uniform probabilities) starting with random trees, with three heated and one cold Markov chains for 2,000,000 generations, sampled at intervals of 100 generations. To determine the point at which the Markov chains reached stationarity, the log-likelihood scores were plotted against generation time, and visually determined when the log-likelihood values reached a stable equilibrium. The parameter estimations (including tree topologies) obtained before reaching the stationarity are discarded as a "burnin", and only 
the trees sampled after that point are considered (Huelsenbeck \& Ronquist 2001).

Posterior probabilities were used to assess node stability. Although generally higher than bootstrap support values, posterior probabilities above the standard 95\% threshold can be taken as indicative of strong node stability (Suzuki et al. 2002, Alfaro et al. 2003, Douady et al. 2003, Simmons et al. 2004, Huelsenbeck \& Rannala 2004).

\section{Results}

The matrix with the 36 species with $28 \mathrm{~S}$ rRNA and wingless sequences (Table 1) had 1,187 characters, of which 359 were parsimony informative. A heuristic search in PAUP resulted in two equally shortest trees of 2,669 steps, in which Ildobates was included in a clade with Desera, Thalpius and Catapiesis with 69\% bootstrap support, none of them with $18 \mathrm{~S}$ rRNA missing (Table 1). The more inclusive clades containing Ildobates had bootstrap support values lower than $50 \%$.

As there was no evidence of a close relationship of Ildobates with any of the species with a missing 18S rRNA sequence (Table 1), a new matrix was build with the 26 species with full data, with 2,959 characters of which 422 were parsimony informative. The heuristic parsimony search resulted in 11 shortest trees of 2,385 steps (CI: 0.382, RI: 0.312), with "Dryptitae" monophyletic (with only $56 \%$ bootstrap support) and Galerita sister to the rest, which formed a polytomy (not shown). After re-weighting the characters, the heuristic search on the 11 original trees resulted in a single tree, in which Thalpius was sister to Ildobates (i.e., a monophyletic Zuphiini), also with very low support (bootstrap $54 \%$, Fig. 1). The bootstrap support for "Dryptitae" using re-weighted characters was very high $(100 \%$, Fig. 1). The tree obtained with Bayesian posterior probabilities had a large polytomy at the base of Harpalinae, although the nodes that were resolved were identical to those of the reweighted parsimony tree (Fig. 1). The nodes defining the relationship of Ildobates had in general higher support, with a posterior probability of 1.0 for "Dryptitae" and 0.94 for the sister relationship

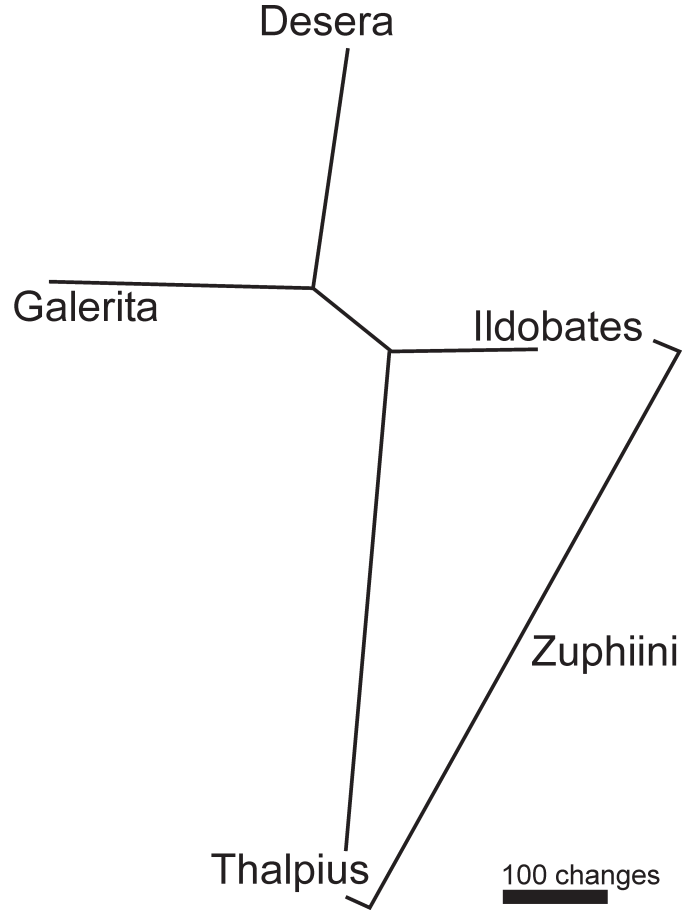

Fig. 2. Un-rooted tree of the exhaustive search on the combined dataset (wingless, 18S rRNA, 28S rRNA) of the four species of "Dryptitae", including hyper-variable regions of the ribosomal genes.

of Ildobates and Thalpius (Fig. 1).

The data matrix of the full sequences of the four species of "Dryptitae" (Galerita, Desera, Thalpius and Ildobates) had 3,846 characters, of which 114 were parsimony informative. In the shortest of the three possible unrooted trees, with 772 steps, the closest relative of Ildobates was Thalpius, with exclusion of Galerita + Desera (i.e., a monophyletic Zuphiini). The same relationship was found with a Bayesian probability search, with a posterior probability of 1.0 (Fig. 2).

\section{Discussion}

Despite the limited taxon sampling (with only one example of each of the potentially relevant groups), all our analyses recovered the monophyly of tribes Zuphiini, Galeritini and Dryptini in what could be called the supertribe "Dryptitae" [i.e., the subfamily Dryptinae of e.g. Serrano (2003)]. This was one of the few nodes with high support among the Harpalinae, both with parsi- 
mony and Bayesian posterior probabilities. The resolution within "Dryptitae" is however low, although all analyses point to a sister relationship of the only included Zuphiini (i.e. Thalpius) and Ildobates, confirming the inclusion of Ildobates among the Zuphiini, as considered in Ortuño et al. (2004) based on a morphological analysis, and in agreement with the traditional taxonomic classification (e.g., Löbl \& Smetana 2003, Serrano 2003).

Zuphiini is a tribe with an almost cosmopoli$\tan$ distribution, with numerous species occupying the subterranean medium (both endogean and troglobitic) (Moore 1995, Casale et al. 1998). It is remarkable that some of these troglobitic species in very distant areas have a strikingly similar overall appearance, such as e.g. Speozuphium and Speothalpius in Australia (Moore 1995, Casale et al. 1998). Our results demonstrate the inclusion of Ildobates among Zuphiini, but are silent about any further detail on relationships within the tribe. It would be most interesting to know if Ildobates is most closely related to similar troglobitic forms in distant geographical areas in which case it could be appropriately called a "relict" species, as it is usually considered (Casale et al. 1998, Ortuño et al. 2004). Alternatively, it could be most closely related with some of the European species, in which case the similarities in external morphology with distant cave species would be an interesting case of parallel or convergent evolution.

Acknowledgements. We greatly thank David Maddison (Arizona) for the unpublished sequence of Desera australis, and A. Izquierdo (MNCN, Madrid) and M. D. Piulach (CID, Barcelona) for help in the sequencing work. We also thank Alberto Sendra (Valencia) and Vicente Ortuño (Madrid) for their help in obtaining the specimens for study.

\section{References}

Alfaro, M. E., Zoller, S. \& Lutzoni, F. 2003: Bayes or Bootstrap? A simulation study comparing the performance of bayesian Markov chain Monte Carlo sampling and bootstrapping in assessing phylogenetic confidence. - Molecular Biology and Evolution 20: 255-266.

Bellés, X. 1987: Fauna cavernícola i intersticial de la Península Ibèrica i les Illes Balears. - Ed. Moll, Mallorca. 207 pp. [In Catalan.]
Casale, A., Vigna-Taglianti, A. \& Juberthie, CH. 1998: Coleoptera Carabidae. - In: Juberthie, C. \& Decu, V. (eds.), Encyclopaedia Biospéologica 2: 1047-1081. Sociéte de Biospéologie, Moulis-Bucarest.

Douady, C. J., Delsuc, F., Boucher, Y., Doolittle, W. F. \& Douzery, J. P. 2003: Comparison of Bayesian and maximum likelihood bootstrap measures of phylogenetic reliability. - Molecular Biology and Evolution 20: 248-254.

Español, F. 1966: Interesantes descubrimientos bioespeleológicos en la provincia de Castellón. - Publ. Inst. Biol. Aplic. Barcelona 40: 67-79. [In Spanish.]

Farris, J. S. 1969: A successive approximations approach to character weighting. - Systematic Zoology 18: 374-385.

Felsenstein, J. 1978: Cases in which parsimony or compatibility methods will be positively misleading. - Systematic Zoology 27: 401-410.

Felsenstein, J. 2004: Inferring phylogenies. — Sinauer, Sunderland. 664 pp.

Huelsenbeck, J. P. \& Rannala, B. 2004: Frequentist properties of Bayesian posterior probabilities of phylogenetic trees under simple and complex substitution models. - Systematic Biology 53: 904-913.

Huelsenbeck, J. P. \& Ronquist, F. 2001: MrBAYES: Bayesian inference of phylogenetic trees. - Bioinformatics 17: 754-755.

Löbl, I. \& Smetana, A. (eds.) 2003: Catalogue of Palaearctic Coleoptera. 1: Archostemata-Myxophaga-Adephaga. - Apollo Books, Stenstrup, Denmark. 819 pp.

Maddison, D. R., Baker, M. D. \& Ober, K. A. 1998: A preliminary phylogenetic analysis of $18 \mathrm{~S}$ ribosomal DNA of carabid beetles (Insecta: Coleoptera). - In: Ball, G. E., Casale, A. \& Vigna-Taglianti, A. (eds.), Phylogeny and classification of Caraboidea (Coleoptera: Adephaga): 229-250. Museo Regionale di Scienze Naturali, Torino. $543 \mathrm{pp}$.

Maddison, D. R., Baker, M. D. \& Ober, K. A. 1999: Phylogeny of carabid beetles as inferred from $18 \mathrm{~S}$ ribosomal DNA (Coleoptera: Carabidae). — Systematic Entomology 24: 103-138.

Maddison, W. P. \& Maddison, D. R. 2000: MacClade, version 4.0. - Sinauer, Sunderland, Massachussets.

Moore, P. 1995: Two remarkable new genera and species of troglobitic Carabidae (Coleoptera) from Nullarbor Caves. - Journal of Australian Entomological Society 34: $159-161$.

Ober, K. A. 2002: Phylogenetic relationships of the carabid subfamily Harpalinae (Coleoptera) based on molecular sequence data. - Molecular Phylogenetics and Evolution 24: 228-248.

Ortuño, V. M., Sendra, A., Montagud, S. \& Teruel, S. 2004: Systématique et biologie d'une espèce paléoendémique hypogée de la péninsule Ibérique: Ildobates neboti Español 1966 (Coleoptera: Carabidae: Dryptinae). — Ann. Soc. Entomol. Fr. (n.s.) 40: 459475. [In French.]

Posada, D. \& Crandall, K. A. 1998: Modeltest: testing the model of DNA substitution. - Bioinformatics 14: $817-818$. 
Rannala, B. \& Yang, Z. 1996: Probability distribution of molecular evolutionary trees: A new method of phylogenetic inference. - Journal of Molecular Evolution 43, 304-311.

Ribera, I., Mateu, J. \& Bellés, X. 2005: Phylogenetic relationships of Dalyat mirabilis Mateu, 2002, with a revised molecular phylogeny of ground beetles (Coleoptera, Carabidae). - Journal of Zoological Systematics and Evolutionary Research 43: 284-296.

Ronquist, F., \& Huelsenbeck, J. P. 2003: MrBayes 3: Bayesian phylogenetic inference under mixed models. - Bioinformatics 19: 1572-1574.

Serrano, J. 2003: Catálogo de los Carabidae (Coleoptera) de la Península Ibérica. Monografías S.E.A., Vol. 9. Sociedad Entomológica Aragonesa, Zaragoza. 130 pp. [In Spanish.]

Shull, V. L., Vogler, A. P., Baker, M. D., Maddison, D. R. \& Hammond, P. M. 2001: Sequence alignment of 18S ribosomal RNA and the basal relationships of Adephagan beetles: Evidence for monophyly of aquatic families and the placement of Trachypachidae. - Syst. Biol. 50: 945-969.

Simmons, M. P., Pickett, K. M. \& Miya, M. 2004: How meaningful are Bayesian support values? - Molecular Biology and Evolution 21: 188-199.

Suzuki, Y., Glazko, G. V. \& Nei, M. 2002: Overcredibility of molecular phylogenies obtained by Bayesian phylogenetics. - Proceedings of the Natural Academy of Science, U.S.A. 99: 16138-16143.

Swofford, D. L., Olsen, G. J., Waddell, P. J. \& Hillis, D. M. 1996: Phylogenetic inference. - In: Hillis, D. M., Moritz, C. \& Mable, B. K. (eds.), Molecular Systematics. 2nd edition: 407-514. Sinauer \& Associates, Sunderland, Massachusetts.

Swofford, D. L. 2002: PAUP*. Phylogenetic Analysis using Parsimony (* and other methods), Version 4.0b10. - Sinauer \& Associates, Sunderland, Massachusetts.

Tavaré, S. 1986: Some probabilistic and statistical problems on the analisis of DNA sequences. - In: Miura, R. M. (ed.), Some mathematical questions in biologyDNA sequence analysis: 57-86. American Math Society, Providence, Rode Island.

Yang, Z. 1993: Maximum likelihood estimation of phylogeny from DNA sequences when substitution rates differ over sites: Approximate methods. - Molecular Biology and Evolution 10: 1396-1401. 